\title{
A Cellular Automata-Based Simulation Tool for Real Fire Accident Prevention
}

\author{
Jacek M. Czerniak (iD, ${ }^{1}$ Hubert Zarzycki, ${ }^{2}$ Lukasz Apiecionek, ${ }^{1}$ \\ Wiesław Palczewski, ${ }^{3}$ and Piotr Kardasz ${ }^{3,4,5}$ \\ ${ }^{1}$ Artificial Intelligence and Robotics Laboratory (AIRlab), Casimir the Great University in Bydgoszcz, \\ Ul. Chodkiewicza 30, 85-064 Bydgoszcz, Poland \\ ${ }^{2}$ University of Information Technology and Management Copernicus, Ul. Inowrocławska 56, 53-648 Wrockaw, Poland \\ ${ }^{3}$ College of Management Edukacja, Department of Computer Science and Quantitative Methods, \\ Ul. Krakowska 56-62, 50-425 Wrocław, Poland \\ ${ }^{4}$ Cluster of Research, Development and Innovation, Ul. Piłsudskiego 74, 50-020 Wrocław, Poland \\ ${ }^{5}$ Foundation for Research, Development and Innovation, Ul. Legnicka 65, 54-206 Wrocław, Poland
}

Correspondence should be addressed to Jacek M. Czerniak; jczerniak@ukw.edu.pl

Received 17 May 2017; Accepted 15 November 2017; Published 14 February 2018

Academic Editor: Andrzej Swierniak

Copyright ( $(2018$ Jacek M. Czerniak et al. This is an open access article distributed under the Creative Commons Attribution License, which permits unrestricted use, distribution, and reproduction in any medium, provided the original work is properly cited.

\begin{abstract}
Many serious real-life problems could be simulated using cellular automata theory. There were a lot of fires in public places which kill many people. Proposed method, called Cellular Automata Evaluation (CAEva in short), is using cellular automata theory and could be used for checking buildings conditions for fire accident. The tests performed on real accident showed that an appropriately configured program allows obtaining a realistic simulation of human evacuation. The authors analyze some real accidents and proved that CAEva method appears as a very promising solution, especially in the cases of building renovations or temporary unavailability of escape routes.
\end{abstract}

\section{Introduction}

Cellular automata are used by some of the IT branches, including the field of artificial intelligence. They consist of a network of cells, each of which is distinguished by some specific state and a set of rules. The change of the current state of a given cell is the outcome of the above-mentioned properties and interrelations with the neighboring cells [1, 2]. The theory of cellular automata was first introduced by an American scientist of Hungarian descent, John von Neumann. He demonstrated, among others, that even simple machines show an ability to reproduce, which was until that time regarded as a fundamental feature of living organisms [3, 4]. For many years cellular automata had been subject to theoretical studies only. With the development of computers and software, optimizing methods based on this approach have been more and more frequently studied and implemented in practice [5]. Due to their versatility, cellular automata are applied in many real-life fields, such as biology, physics, and mathematics and in various fields of IT, such as cryptography or computer graphics $[6,7]$.

1.1. Application of Cellular Automata. Cellular automata have been applied in practice, for example, in simulation of the street traffic, where specifically defined cellular automaton controls the traffic [8-10]. The vehicle flow is managed basically at the specific segment of a given traffic intensity [11]. This applies, for instance, to the traffic intensity control on highways of the Ruhr in Germany. The monitoring centers designed exclusively for that purpose collect the data from selected sections of the highways [12-16]. The information thus obtained is analyzed and used for preparing short-time simulations of the traffic intensity by means of cellular automata. The projects websites publish the statistical information about the studies performed on the behavior of drivers who were prewarned about possible 

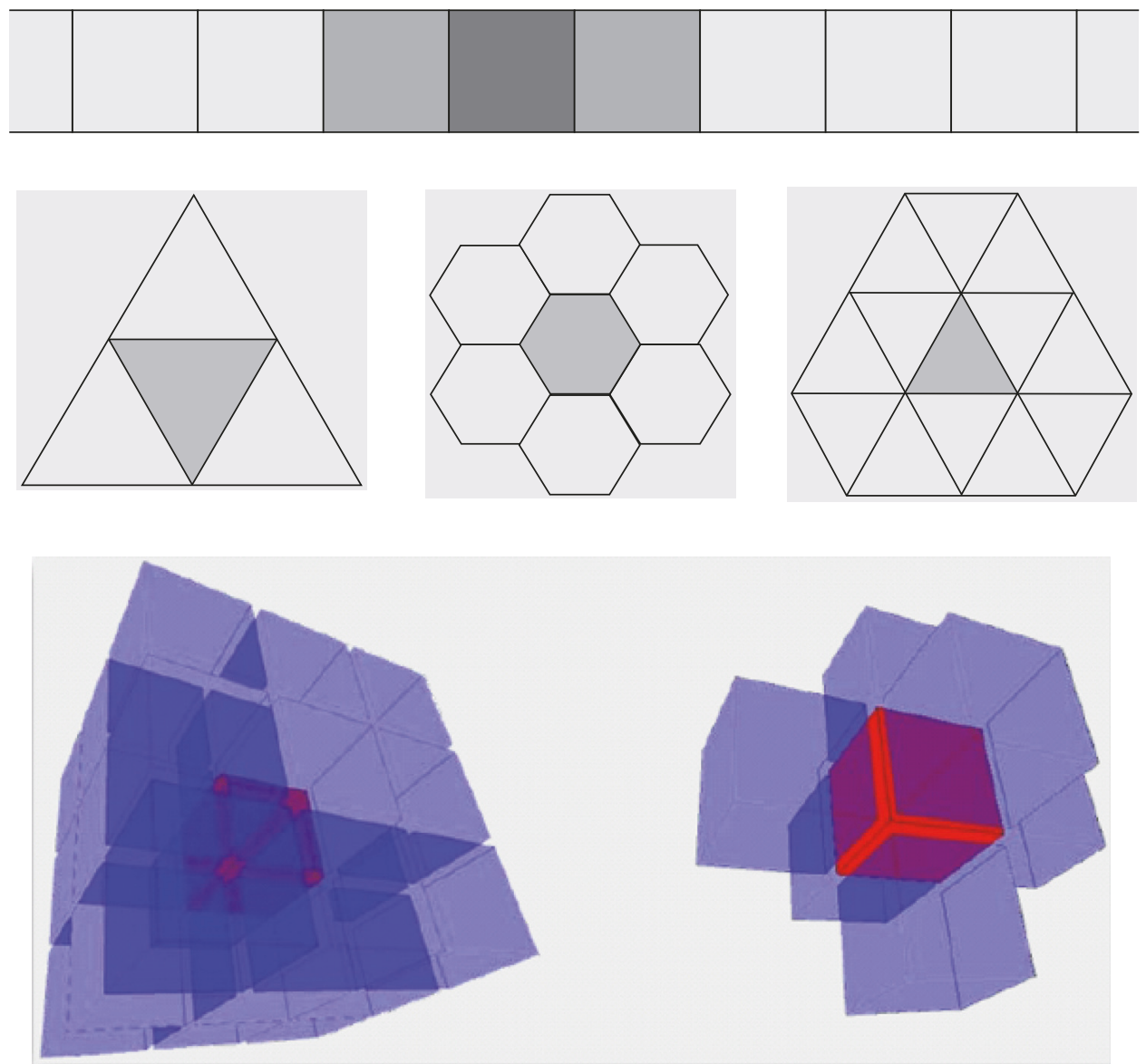

FIGURE 1: Types of grids: 1D, 2D, and 3D [source: [14]].

traffic problems [17] that might occur over several following hours [6]. Another example of cellular automata application is demographic simulations for a given region. The aim of such simulations is to generate a model showing the size of the population at a given area in a form of a map of the forecasted population density. Such simulations can be based on the well-known "Game of Life" [18]. By introducing some modification to the algorithm, it is possible to monitor the behavior of the surrounding cells [7]. Other examples of cellular automata implementations include image processing, generation of textures, simulation of waves, wind, and people evacuation process as well as a simulation program, developed for the purpose of this study [19-23]. The aim of the proposed algorithm is to generate the simulations of patterns of human escape from the building on fire with a given number of exits and fire sources [24-27].

1.2. The Grid of Cellular Automata. A grid or a discrete space, where cellular automata evolution takes place, consists of a set of identical cells [26, 30, 31]. Each of the cells is surrounded by the same number of neighbors and can assume the same number of states [32-35]. There are three structural factors which significantly influence the grid form and, as a consequence, the behavior of the entire cellular automaton $[8,17,23,32-35]$ : (i) the size of the space which depends on the magnitude of the studied problem, the examples of which are shown in Figure 1 (grids 1D, 2D, and 3D);

(ii) the provision of regularity, which requires the grid to be filled entirely with identical cells;

(iii) the number of neighbors (dependent on both abovementioned factors).

In this article, the authors present the possibility of simulating real fire accident to prevent huge fire accidents. For this purpose authors used Cellular Automata Evaluation method, CAEva in short. This paper has following organization. Section 2 presents the idea of forecasting the fire hazard, two real accidents' description, and CAEva simulation method with their boundary conditions and transfer function. Section 3 presents the experiment results when the mentioned two real fire accidents were simulated. Finally Section 4 consists of final conclusions.

\section{Forecasting the Fire Hazard}

2.1. Fire Accidents in Public Places. Fires are one of the most uncontrollable calamities, especially when they happen indoors. Thus, regardless of the edifices function whether it is a residential, business, or any other kind of building, 
TABLE 1: Fire accidents in public places.

\begin{tabular}{lccc}
\hline Name & Year & Fatalities & Injuries \\
\hline Study Club fire & 1929 & 22 & 50 \\
Cocoanut Grove fire & 1942 & 492 & 166 \\
Karlslust dance hall fire & 1947 & $80-88$ & 150 \\
Stardust fire & 1981 & 48 & 214 \\
Alcal 20 nightclub fire & 1983 & 82 & 27 \\
Ozone Disco Club fire & 1996 & 162 & 95 \\
Gothenburg discothque fire & 1998 & 63 & 213 \\
Volendam New Years fire & 2001 & 14 & 241 \\
Canec£o Mineiro nightclub fire & 2001 & 7 & 197 \\
Utopa nightclub fire & 2002 & 25 & 100 \\
The Station nightclub fire & 2003 & 100 & 230 \\
Wuwang Club fire & 2008 & 43 & 88 \\
Santika Club fire & 2009 & 66 & 222 \\
Lame Horse fire & 2009 & 156 & $\leq 160$ \\
Kiss nightclub fire & 2013 & 231 & 168 \\
\hline
\end{tabular}

its design must comply with fire regulations. The width of corridors, number of emergency exits, and the permissible number of people staying inside at the same time have a grave impact on the safety of its users. Simple presence of the doors on floor plan is not sufficient; they have to be open. In many cases the high number of casualties stemmed from the emergency exit doors being locked. In the past decades there have been a number of disastrous fires in public places like restaurants and nightclubs. Table 1 presents some examples of such accidents and lists the numbers of victims. As you can see from the data provided, there have been many fires in entertainment clubs over the years, causing many injuries, irrespective of whether they occurred decades ago (1942) or in recent times (2013).

2.2. The Case of Kiss Nightclub Fire Accident. The event called "Aglomerados" began on Saturday, 26 January 2013, at 23:00 UTC at the Kiss nightclub. In the club there were students of six universities and people from technical courses at the Federal University of Santa Maria [36]. In the early morning hours of the following day, conflagration took place while the students were holding a freshers' ball and a panic broke out. Witnesses testified that the cause of the fire was either a flare of fireworks lit by the members of a music band playing during the party. The fire caused the roof to collapse in several parts of the building, trapping many people inside. Firefighters found numbers of bodies in the club's bathroom. At the moment of conflagration there were about 2,000 people inside the club. This number doubles the buildings maximum capacity of 1,000 . At least 231 people died and hundreds more were injured in this disaster. Many fatalities were apparently caused by smoke inhalation, while other victims were trampled in the rush for the exits. Figure 2 presents the scheme of the Kiss nightclub.

2.3. The Cocoanut Grove Fire Accident. The Cocoanut Grove was a restaurant built in 1927 and located at 17 Piedmont

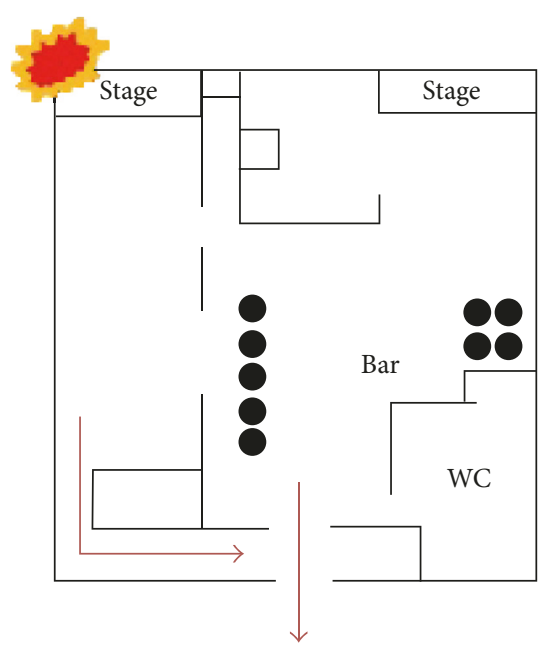

FIgURE 2: Kiss nightclub scheme [28].

Street, near Park Square, in downtown Boston, Massachusetts $[29,37]$. According to Prohibition, it was very popular in the 1920s. The building structure was single-storey, with a basement beneath. The basement consists of a bar, kitchen, freezers, and storage areas. The first floor contained a large dining room area and ballroom with a bandstand, along with several bar areas separate from the ballroom. The dining room also had a retractable roof for use during warm weather to allow a view of the moon and stars. The main entrance to the Cocoanut Grove was via a revolving door on the Piedmont Street side of the building. On Saturday, November 28,1942 , there was a very large fire accident. During that evening, a busboy had been ordered to fix a light bulb located at the top of an artificial palm tree in the corner of the basement bar. A moment later decorations started burning. As other furnishings ignited, a fireball of flame and toxic gas raced across the room towards the stairs. The revolving door became jammed due to the crush of panicked patrons. Lots of people stuck in fire. It was later estimated that more than 1000 persons were inside the Grove at the time of the fire. The final death count established by Commissioner Reilly was 490 dead and 166 injured, but the number of injured people was a count of those treated at a hospital and later released while many people were injured but did not seek hospitalization. Figure 3 presented the scheme of the Cocoanut Grove.

2.4. CAEva Simulation Method. CAEva simulation method is a program prepared for the purpose of rehearsing the fire escape scenarios in buildings [7]. It helps to compare various simulation results and to draw suitable conclusions. The program has been implemented in the $\mathrm{C}++$ Builder environment, which is an object-oriented programming tool in Windows environment and is available free of charge at the AIRlab web site [38]. The program allows drawing a board of any size, including the plan of a single-storey building, to locate people inside and to indicate the source of fire. The board consists of a grid of cells. Each cell can assume only 


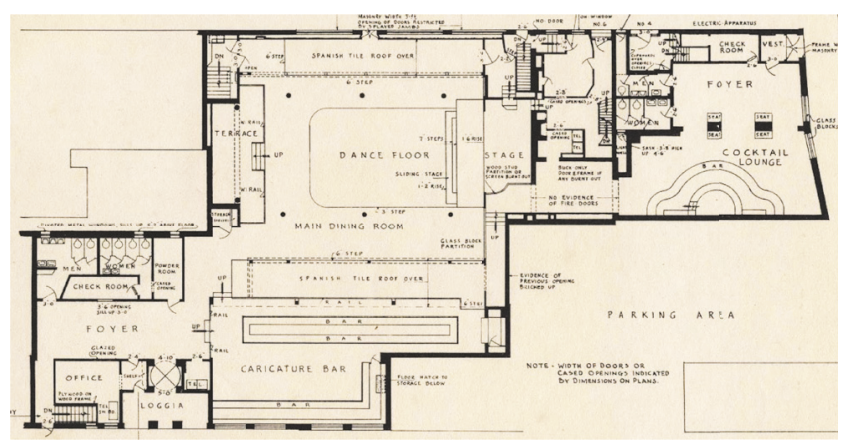

Figure 3: The Cocoanut Grove scheme [29].

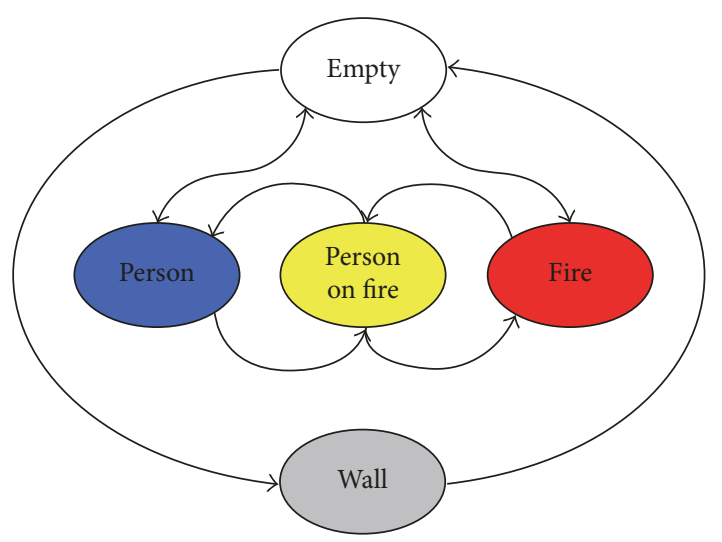

Figure 4: Diagram of cell states.

one of the following states: fire, wall, person, person on fire, or an empty cell. Figure 4 presents the diagram of states for a single cell in the fire simulation automaton.

2.5. Boundary Conditions. The discrete space, where various evolutions of cellular automata take place, includes a $d$ dimensional, theoretically infinite grid. As this kind of grid cannot be implemented into computer application, it is represented in a form of a limited table. Therefore, it is necessary to set boundary conditions at the grid borders, that is, at the table limits. The set of basic conditions is shown in Figure 5. These conditions are analogous after grid rotation of 90 degrees, so further arrangements were skipped as trivial. The following rules were used for the simulation of the cell motion in the wall direction:

(i) straight motion: the state of the cell remains unchanged,

(ii) diagonal motion: the state of the cell changes into an empty one, since the angle of incidence equals the angle of rebound, the state of the cell in the mirror image shall change into the state of the cell which initiated the motion,

(iii) motion conditions:

(iv) motion is possible if the target cell is in the empty state. Otherwise, the cell will not change its state, (v) the attempt of the motion of the cell in "person" state to the cell in "fire" state increases the number of burns of the initiating cell.

A special case is an attempt of the motion from the corner of the board. A rebound in three initiating directions does not change the state of a cell, but it may change it change as a result of an attempt of the motion in the consecutive five directions. It should be also noted that motion rules and conditions apply to the cells in the "person" state as well as in the "fire" state. The fields to which the motion cannot be executed are the cells in the "wall" state. Rebound conditions occur at the edge of the cellular automata grid, which constitutes a barrier from which moving virtual objects rebound (in visual sense). Those conditions are used to simulate encased empirical spaces.

2.6. Transfer Function. The evolution of cellular automata takes place in discrete time determining consecutive processing cycles. Each discrete moment $t=0,1,2, \ldots, n$ is used for updating the state of individual cells; thus each automaton is a dynamic object over time. In every iteration, the transfer function can process (calculate) all the cells in the grid one by one according to specific rules. Each processed cell receives its new state based on the calculation of its current state and states of the neighboring cells. Transfer rules and the state space, as well as the defined neighborhood, are inherent elements of the cellular automata evolution process. Once executed, the program displays main screen ready to draw the building plan and to arrange individual elements inside. Once the board is drawn and all the components are arranged, the user can start the configuration of fire and people parameters and setting of the group effect. Fire parameters are as follows:

(i) fire goes out alone if the number of neighbors is less than 1 ,

(ii) fire goes out from overpopulation if the number of neighbors is more than 3 ,

(iii) new fire is generated when the number of neighbors is at least 3,

(iv) fire is generated when the number of neighbors is less than or equal to 4 . Parameters concerning people are as follows:

(v) probability that a person goes towards the exit in default state is 50 ,

(vi) number of burns resulting in death is 5,

(vii) group effect is On/Off.

There are points in the screen simulating people escaping towards the exit and the propagating fire. All the events are recorded in the table of statistics. They include the number of people remaining within the board, saved from and died in the fire or by crushing $[39,40]$. That data obtained enable drawing conclusions from the experiments [41, 42].

2.7. Implementation of OFN Notation to Fuzzy Observation of Real Fire Accident. The use of ordered fuzzy numbers in 


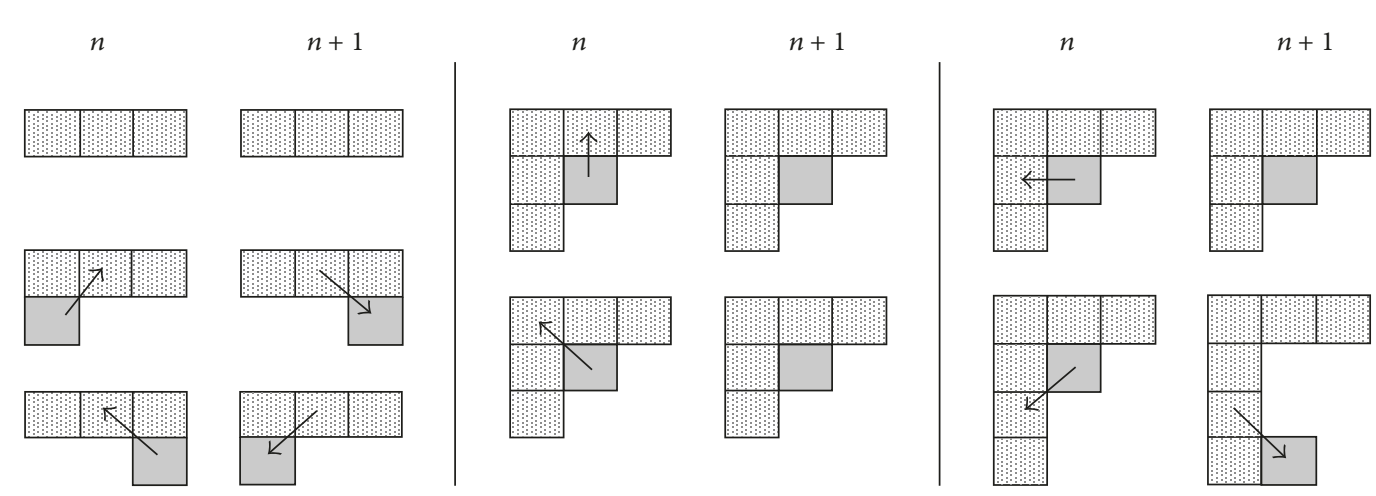

FIGURE 5: Boundary conditions (rebound from the grid edges).

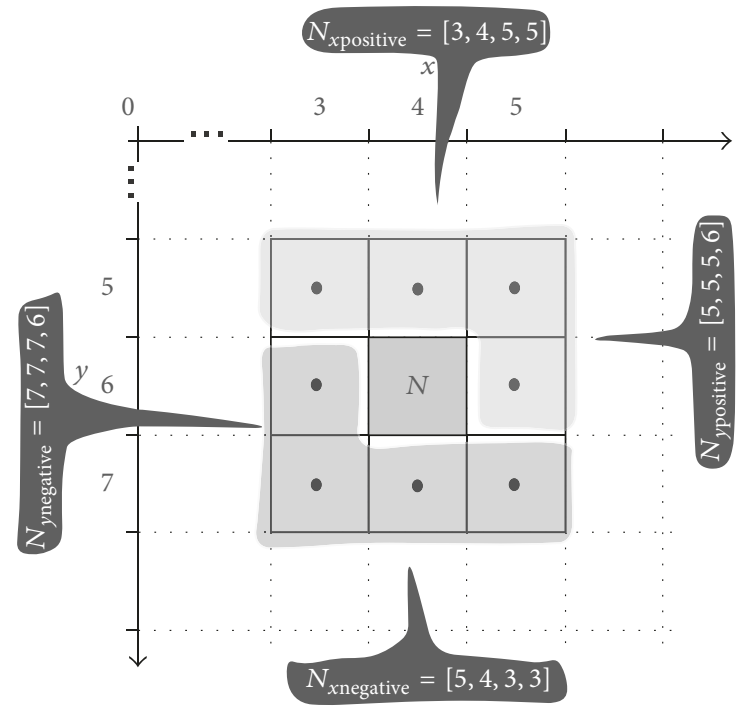

FIGURE 6: Example of move in simulation algorithm.

cellular automation seems to be a natural step. There are many notations of fuzzy numbers that are introduced by Zadeh [43], Klir [44], Dubois et al. [45], and Kłopotek et al. [23, 46, 47], among others. Since we have in this case a two-dimensional apparatus in which Moore's neighborhood is additionally used, there are eight available moves from cells $N i, j$. An example of this situation is shown in Figure 6.

There is a part of the neighborhood that is closer to the exit, and the other part closer to the group of cells in the human state $[20,48]$. Thus, there are two possible sets of movements for this cell in question, depending on the determinant $[27,49,50]$. Since each of the sets is a fourelement, then the notation of fuzzy numbers called ordered fuzzy numbers introduced by Kosiński is suitable for its description [51, 52]. After the death of the creator OFNs in some works are also called Kosiński's Fuzzy Numbers $[23,47,48,53,54]$. In this notation, the fuzzy number $A$ in general has the shape of a trapezoid described by coordinates $[f A(0), f A(1), g A(1), g A(0)]$, which is presented in Figure 8.

Arrow in Figure 8 shows directing that reflects the order of the individual coordinates. On such fuzzy numbers, it is possible to perform arithmetic operations described in literature $[47,55]$ :

(i) addition: $A+B=(f+e, g+h)=C$

$$
\begin{aligned}
C & \longrightarrow[f(0)+e(0), f(1)+e(1), g(1)+h(1), g(0) \\
& +h(0)],
\end{aligned}
$$

(ii) scalar multiplication: $C=\lambda A=(\lambda f, \lambda g)$

$$
C \longrightarrow[\lambda f(0), \lambda f(1), \lambda g(1), \lambda g(0)]
$$

(iii) subtraction: $A-B=(f-e, g-h)=C$

$$
\begin{aligned}
C & \longrightarrow[f(0)-e(0), f(1)-e(1), g(1)-h(1), g(0) \\
& -h(0)],
\end{aligned}
$$

(iv) multiplication: $A * B=(f * e, g * h)=C$

$$
\begin{aligned}
C & \longrightarrow[f(0) * e(0), f(1) * e(1), g(1) * h(1), g(0) \\
& * h(0)],
\end{aligned}
$$

(v) division: $A / B=(f / e, g / h)=C$

$$
C \longrightarrow\left[\frac{f(0)}{e(0)}, \frac{f(1)}{e(1)}, \frac{g(1)}{h(1)}, \frac{g(0)}{h(0)}\right]
$$

A given set of possible moves in Moore's neighborhood from the cell $N_{i, j}$ to cell $N_{(i, j)}^{\prime}$ is shown in Figure 9. Depending on the settings of the algorithm, the traffic determinant can be

(i) going towards the nearest exit,

(ii) getting the nearest gathering of people.

The determinant will be related to the fuzzy number in the OFN notation [46].

Definition 1. Let $(N x, N y)$ be two pairs of fuzzy numbers. Directing will be positive for a subset of moves closer to the indicated determinant:

$$
\begin{aligned}
& N x_{\text {positive }}[i-1, i, i+1, i+1], \\
& N y_{\text {positive }}[j-1, j-1, j-1, j] .
\end{aligned}
$$


TABLE 2: Results of simulation with CAEva method for the Kiss nightclub.

\begin{tabular}{|c|c|c|c|c|c|c|}
\hline \multirow{4}{*}{ Number of people } & \multicolumn{6}{|c|}{ Group effect } \\
\hline & & No & & & Yes & \\
\hline & \multicolumn{6}{|c|}{ Probability of people heading towards the exit } \\
\hline & $25,00 \%$ & $50,00 \%$ & $75,00 \%$ & $25,00 \%$ & $50,00 \%$ & $75,00 \%$ \\
\hline Died & 649 & 471 & 325 & 506 & 455 & 428 \\
\hline Trampled & 127 & 196 & 208 & 323 & 250 & 196 \\
\hline Saved from fire & 224 & 333 & 467 & 171 & 295 & 376 \\
\hline
\end{tabular}

TABLE 3: A comparison of the CAEva method results with actual numbers for the Kiss nightclub.

\begin{tabular}{|c|c|c|c|c|c|c|}
\hline \multirow{4}{*}{ Relative error [\%] } & \multicolumn{6}{|c|}{ Group effect } \\
\hline & & No & & & Yes & \\
\hline & \multicolumn{6}{|c|}{ Probability of people heading towards the exit } \\
\hline & $25,00 \%$ & $50,00 \%$ & $75,00 \%$ & $25,00 \%$ & $50,00 \%$ & $75,00 \%$ \\
\hline Died & 239 & 68 & 5 & 91 & 18 & 17 \\
\hline Trampled & 83 & 64 & 5 & 281 & 221 & 58 \\
\hline Saved from fire & 58 & 26 & 2 & 79 & 54 & 11 \\
\hline
\end{tabular}

A pair of coordinates that are more distant from the determinant will be denoted by negative directing:

$$
\begin{aligned}
& N x_{\text {negative }}[i+1, i, i-1, i-1], \\
& N y_{\text {negative }}[j+1, j+1, j+1, j] .
\end{aligned}
$$

A subset of cells to which further motion can be determined is a pair of fuzzy numbers satisfying the following rules:

$$
\begin{aligned}
& \text { IF } N x_{\text {positive }} * N x_{\text {negative }} \text { is positive THEN } N x= \\
& N x_{\text {positive }} \text { ELSE } N x=N x_{\text {negative }} \text { IF } N y_{\text {positive }} * \\
& N y_{\text {negative }} \text { is positive THEN } N y=N y_{\text {positive }} \text { ELSE } \\
& N y=N y_{\text {negative }}
\end{aligned}
$$

From this set of pairs described $\left(N_{x}^{\prime}, N_{y}^{\prime}\right)$, which represents the four possible moves in the next evolution of the cellular automaton, one pair of coordinates is drawn. By default, the fields in which the traffic is impossible must be eliminated from the list. If no movement is possible in any of the four cells, the cell state will not change. This symbolizes a situation in which a person remains motionless.

\section{The Experiment with CAEva Method}

The authors launched a simulation of the Kiss nightclub scenario in CAEva program. They placed people inside and set the fire. The building is comprised of seven rooms and there was only one exit. The blue points mark people and the red ones fire. Several tests were performed based on this scheme and the assumed conditions were as follows: the aim of the test was to simulate a fire of the building, based on certain rules and relations. Setting of the following parameters, selection of versions, and inherent rules altogether make up an environment which affect the mortality rate. The variables were

(i) the layout of the building floors, including the number and location of doors, (ii) distribution of a defined number of people inside the building at specified places,

(iii) setting the fire parameters:

(a) the fire goes out alone if there are no neighbors,

(b) the fire goes out because of overpopulation if there are more than 3 neighbors,

(c) new fire is generated when there are at least 3 neighbors, but not more than 4 ,

(iv) setting of the parameters for people (live cells):

(a) number of burns resulting in death is by default set to 5 ,

(v) location of the fire source on the board,

(vi) specifying the probability of people heading towards the exit (three options): $25 \%, 50 \%$, and $75 \%$,

(vii) specifying whether people move towards the exit in groups (two options): with or without a group effect.

Figure 10 presents Kiss nightclub schema before the simulation process was started. The red squares represent fire while the blue ones represent people. Figure 11 presents Kiss nightclub schema after completing the simulation. Figure 12 presents Cocoanut Grove schema before the simulation process was started. The red squares represent fire while the blue ones represent people. Figure 13 presents Cocoanut Grove schema after completing the simulation. The simulation was made two hundred times for each condition; there were six conditions which give 1200 simulations for one fire accident. Table 2 presents the average results of the performed simulation. Taking into account the real data concerning the number of fatalities in the Kiss nightclub fire, the outcome which was closest to the actual death toll was achieved using $75 \%$ probability of people going towards the exit and with group effect off. Table 3 compares the average results with real numbers. 
TABLE 4: Results of simulation with CAEva method for the Cocoanut Grove nightclub.

\begin{tabular}{|c|c|c|c|c|c|c|}
\hline \multirow{4}{*}{ Number of people } & \multicolumn{6}{|c|}{ Group effect } \\
\hline & & No & & & Yes & \\
\hline & \multicolumn{6}{|c|}{ Probability of people heading towards the exit } \\
\hline & $25,00 \%$ & $50,00 \%$ & $75,00 \%$ & $25,00 \%$ & $50,00 \%$ & $75,00 \%$ \\
\hline Died & 649 & 471 & 325 & 506 & 455 & 428 \\
\hline Trampled & 127 & 196 & 208 & 323 & 250 & 196 \\
\hline Saved from fire & 224 & 333 & 467 & 171 & 295 & 376 \\
\hline
\end{tabular}

TABle 5: A comparison of the CAEva method results with actual numbers for the Cocoanut Grove nightclub.

\begin{tabular}{|c|c|c|c|c|c|c|}
\hline \multirow{4}{*}{ Number of people } & \multicolumn{6}{|c|}{ Group effect } \\
\hline & & No & & & Yes & \\
\hline & \multicolumn{6}{|c|}{ Probability of people heading towards the exit } \\
\hline & $25,00 \%$ & $50,00 \%$ & $75,00 \%$ & $25,00 \%$ & $50,00 \%$ & $75,00 \%$ \\
\hline Died & 32 & 4 & 34 & 3 & 7 & 13 \\
\hline Trampled & 23 & 18 & 25 & 94 & 51 & 18 \\
\hline Saved from fire & 33 & 0 & 40 & 49 & 12 & 13 \\
\hline
\end{tabular}

As you can see in Table 2, the increase in the probability of people heading to the exit reduces the number of people who die as a result of fire. The number of victims decreases only when the group effect is on. Furthermore the overall number of people who have survived a fire also increases as the probability of people moving towards the exit increases.

As shown in the Table 3, the smallest relative error was obtained in the absence of group effect and at the value of $75 \%$ of the people heading to the exit. The biggest errors were achieved with the group effect enabled and with the $25 \%$ probability of people going to the exit. This could mean that in the event of this fire, the group effect did not work, and people were looking for a way out by themselves.

As you can see in Table 4, here also the increase in the probability of going to the exit of the premises has reduced the number of people who died in the fire. Table 5 compares the average results with real numbers. The smallest error was obtained for the disabled group effect, but with a value of $50 \%$ of people heading to the exit. This may mean that, in the event of a fire in this club, group effect also did not work, but people did not hurry to leave the club, which caused a tragic effect.

The mortality rate depends on the place of the fire outbreak. If the fire blocks any room, then the people staying there are not able to escape and to reach the exit even if they move towards it with $100 \%$ probability. The group effect used in the program does not necessarily help in escape of people from the building. It can generate crowd, as people are looking for others to form groups and thus trampling can occur. When a person does not have any direction when he/she could move, he/she is trampled. In Figures 6-9, the place of fire and the fire spread are marked in red. In contrast, blue indicates the location of people at the start of an event, a fire.

\section{Conclusions}

As one can see, performed simulations can help understand how people behaved at the time of the fire, whether they followed the crowd in search of an exit, whether they were acting alone, or were they determined enough to find a way out. In one case, people showed a higher level of determination (75\% probability of going towards the exit), while in the second case the level was lower (50\%). Simulations can be used as a warning during security level analysis, but also as an element of a detailed analysis of the events that occurred.

The comparison of the proposed method with actual case demonstrated that it is extremely difficult to create a simulation of fire escape scenario. The most challenging element is the people behavior, which may become stochastic and unpredictable. The authors of this study managed to recreate the scenario of the escape of people from a building by means of cellular automata, the implementation of which was the object of this paper. Using an appropriate configuration of the program: determining the probability of a person heading towards the exit, the fire parameters and on/off setting of the group effect allow to drawing the following conclusions. When the group effect is applied in the program the number of people who die as a result of trampling is larger than in the case when this effect is disabled. The mortality rate rises when people are not able to move in any direction, which is a result of individuals gathering in groups that create areas of high density, where trampling often occurs. The results which proved to be closest to the actual numbers were achieved when the 


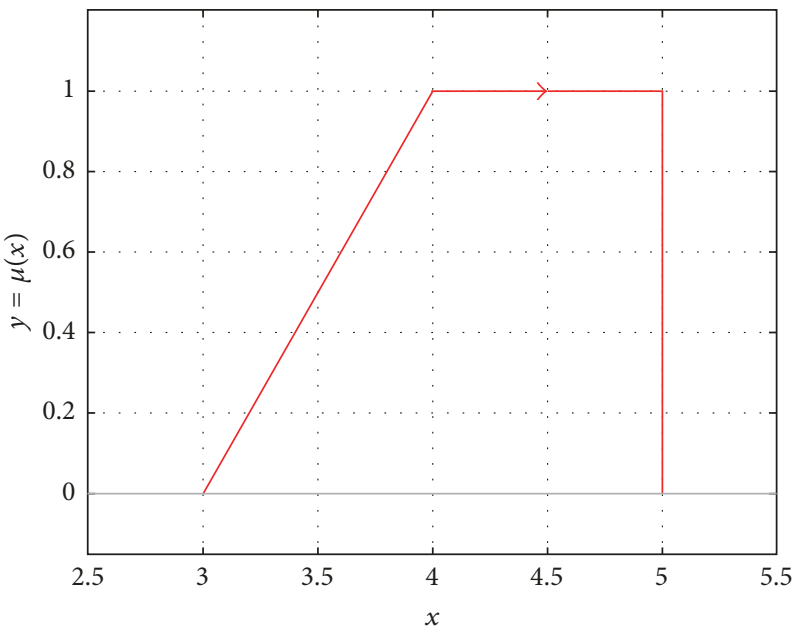

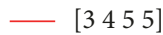

(a)

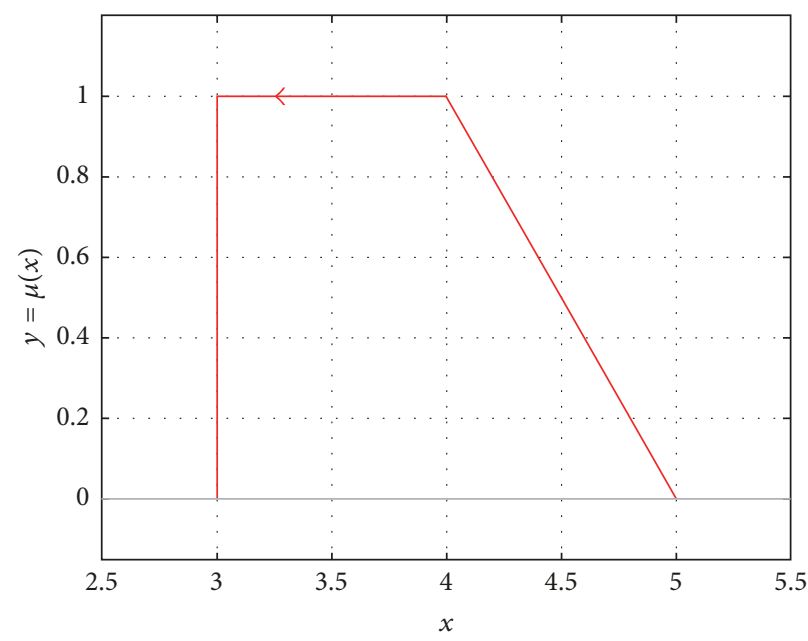

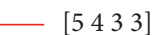

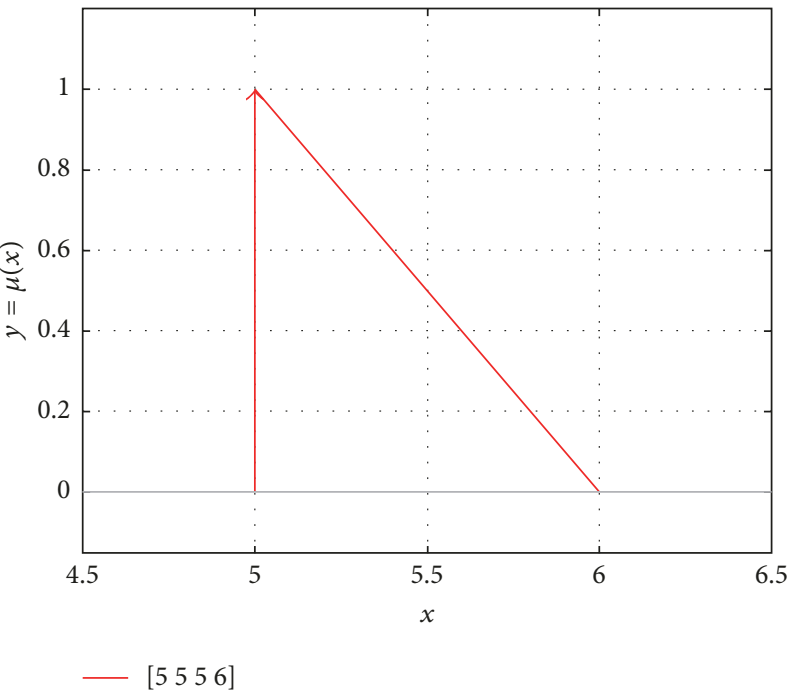

(b)

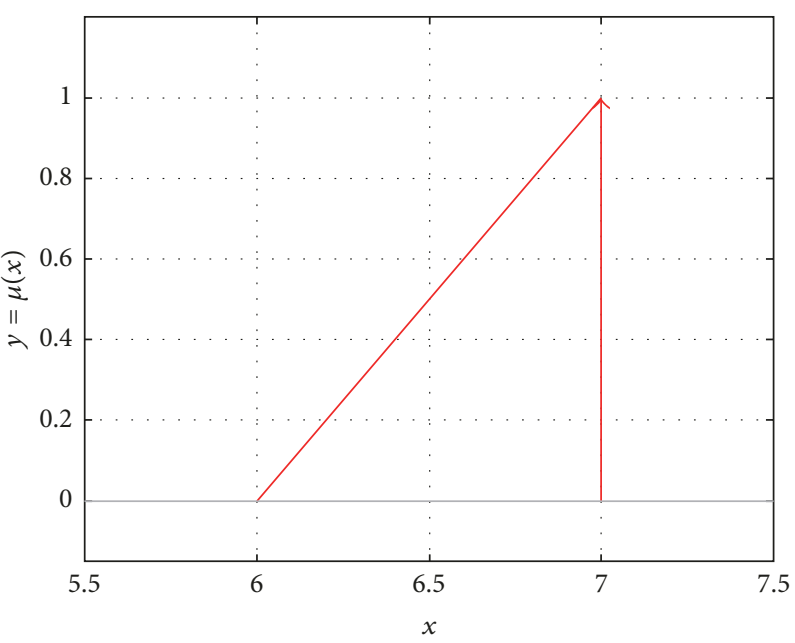

$\left[\begin{array}{llllllllllll}7 & 7 & 7 & 6\end{array}\right]$

(c)

(d)

FIgUre 7: The OFN visualization of $N x$-positive (a), $N y$-positive (b), $N x$-negative (c), and $N y$-negative (d).

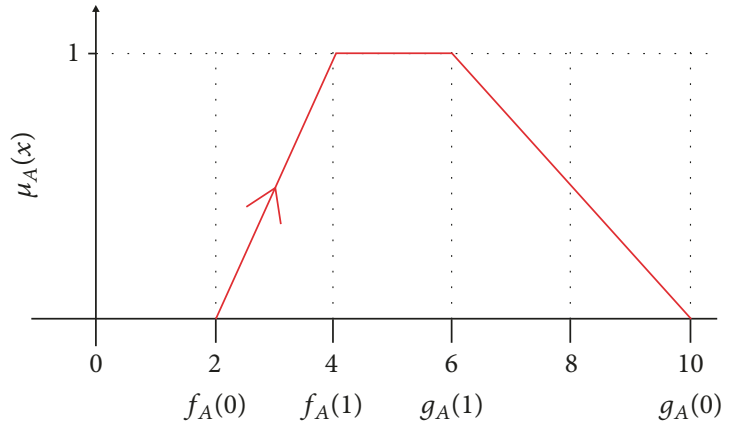

FiguRE 8: Fuzzy number with the extension. 


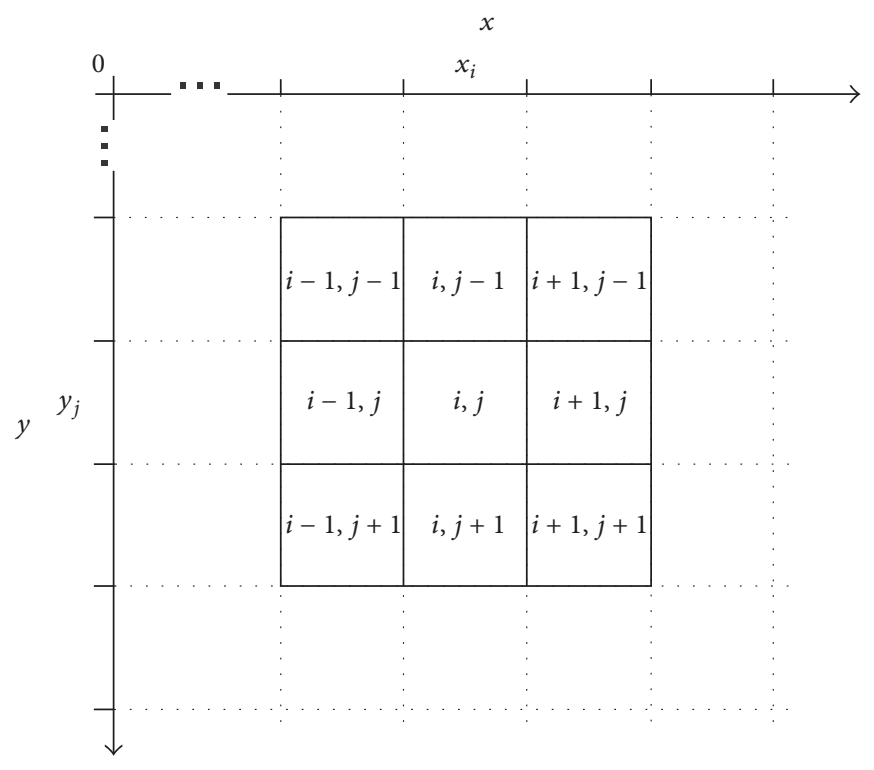

Figure 9: Possible move.

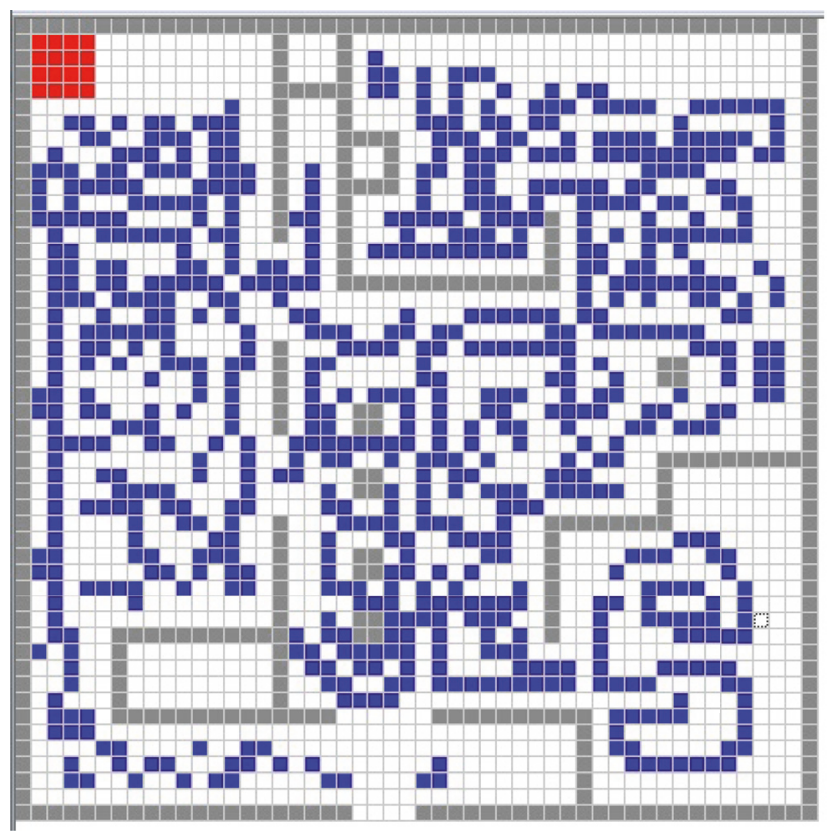

FIGURE 10: Kiss nightclub schema with people and fire in CAEva program.

value of probability with which people escape was around $50-75 \%$. The hindrances that affect the decision making process during the evacuation include, among others, limited visibility due to the smoke, resulting from combustion of flammable materials, high temperature, and toxic gases. The result achieved in the CAEva method can provide valuable information for architects and building constructors. The results obtained from the program confirm the thesis that insouciant or unlawful blocking of escape routes inside

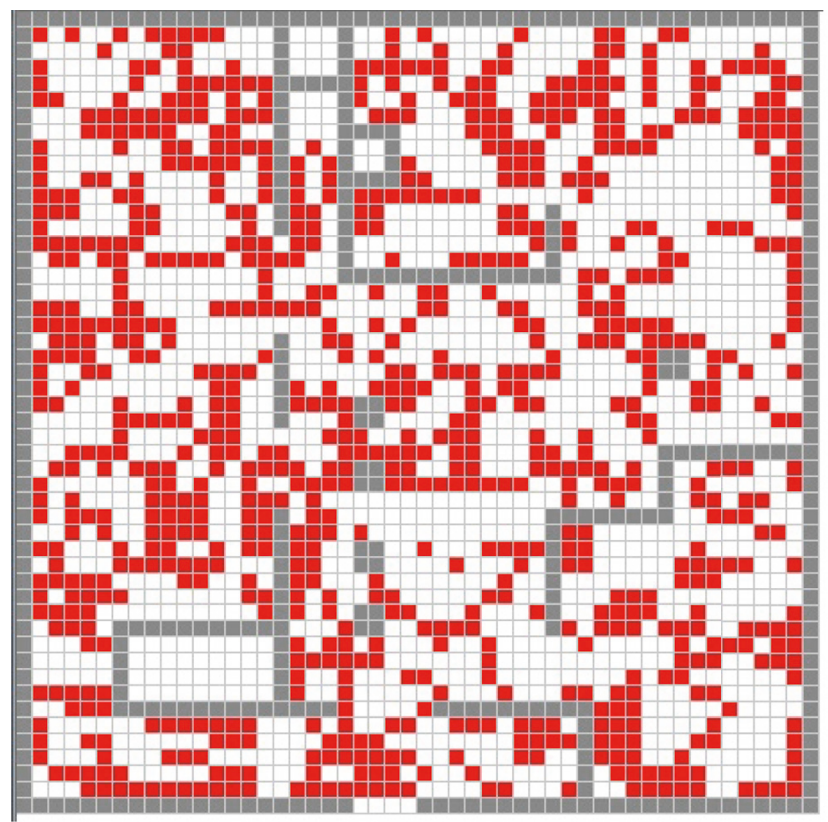

FIGURE 11: CAEva program after simulating fire in Kiss nightclub.

buildings may have tragic consequences at each stage of the building operation. The people who are responsible for fire safety and structural safety inspections may apply such tools to justify their decisions that sometimes could seem to be too strict. To make the simulation even more realistic, it is worth considering the option of automatic change of the parameter related to the probability of a person moving towards the exit during the simulation. Adding further conditions in order to provide more accurate results is also 


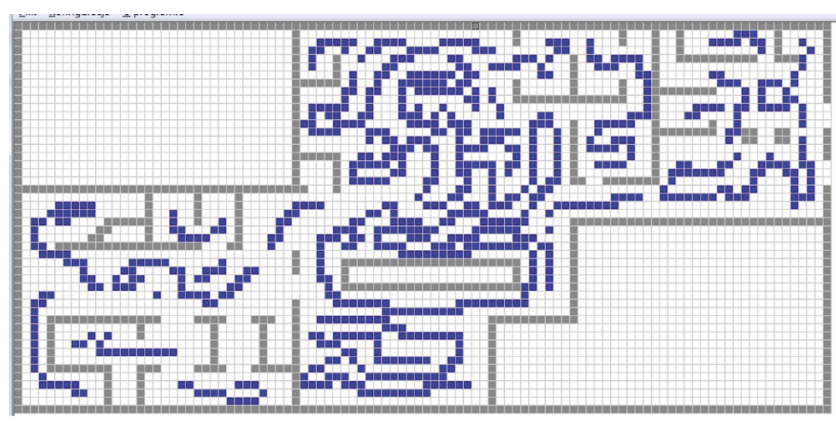

Figure 12: The Cocoanut Grove schema with people and fire in CAEva program.

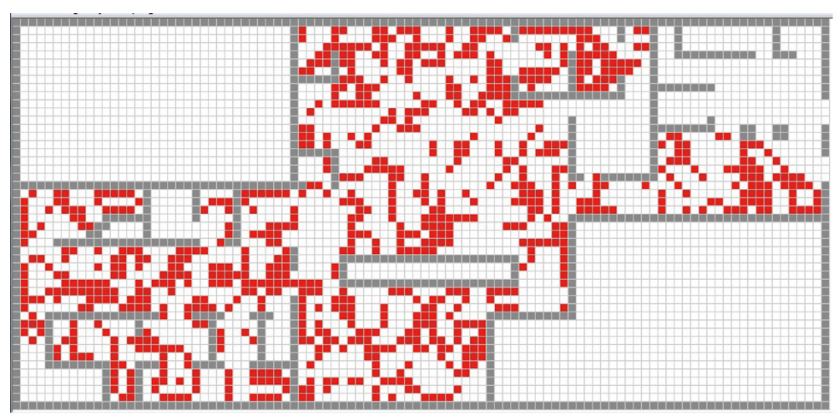

Figure 13: CAEva program after simulating fire in The Cocoanut Grove.

possible. The future experiments should take this fact into account.

\section{Conflicts of Interest}

The authors declare that there are no conflicts of interest regarding the publication of this paper.

\section{References}

[1] E. Mikolajewska and D. Mikolajewski, "Exoskeletons in neurological diseases - current and potential future applications," Advances in Clinical and Experimental Medicine, vol. 20, no. 2, pp. 227-232, 2011.

[2] E. Mikolajewska and D. Mikolajewski, "E-learning in the education of people with disabilities," Advances in Clinical and Experimental Medicine, vol. 20, no. 1, pp. 103-109.

[3] X. Yang, B. Wang, and Z. Qin, "Floor field model based on cellular automata for simulating indoor pedestrian evacuation," Mathematical Problems in Engineering, vol. 2015, Article ID 820306, 10 pages, 2015.

[4] E. A. Lim and W. C. Tan, "Simulating evacuations with obstacles using a modified dynamic cellular automata model," Journal of Applied Mathematics, vol. 2012, Article ID 765270, 17 pages, 2012.

[5] J. M. Czerniak, W. Dobrosielski, H. Zarzycki, and Ł. Apiecionek, "A proposal of the new owlANT method for determining the distance between terms in ontology," Advances in Intelligent Systems and Computing, vol. 323, pp. 235-246, 2014.
[6] B. Płaczek, "Performance evaluation of road traffic control using a fuzzy cellular model," Lecture Notes in Computer Science (including subseries Lecture Notes in Artificial Intelligence and Lecture Notes in Bioinformatics): Preface, vol. 6679, no. 2, pp. 5966, 2011.

[7] J. M. Czerniak, L. Apiecionek, H. Zarzycki, and D. Ewald, "Proposed CAEva simulation method for evacuation of people from a buildings on fire," in Novel Developments in Uncertainty Representation and Processing, pp. 315-326, Springer, 2016.

[8] V. Terrier, "Two-dimensional cellular automata and their neighborhoods," Theoretical Computer Science, vol. 312, no. 2-3, pp. 203-222, 2004.

[9] S. Wolfram, A New Kind of Science, Wolfram Media, Champaign, Ill, USA, 2002.

[10] I. Rojek, M. Kowal, and A. Stoic, "Predictive compensation of thermal deformations of ball screws in cnc machines using neural networks," Tehnicki Vjesnik, vol. 24, no. 6, 2017.

[11] [link]. URL http://www.autobahn.nrw.de/.

[12] D. Chowdhury, L. Santen, and A. Schadschneider, "Statistical physics of vehicular traffic and some related systems," Physics Reports, vol. 329, no. 4-6, pp. 199-329, 2000.

[13] N. Yu, G. de Roo, M. de Jong, and S. Storm, "Does the expansion of a motorway network lead to economic agglomeration? evidence from China," Transport Policy, vol. 45, pp. 218-227, 2016.

[14] K. Nagel and M. A. Schreckenberg, "Cellular automaton model for freeway traffic," Journal de Physique, vol. 2, pp. 2221-2229, 1992.

[15] S.-C. Lo and C.-H. Hsu, "Cellular automata simulation for mixed manual and automated control traffic," Mathematical and Computer Modelling, vol. 51, no. 7-8, pp. 1000-1007, 2010.

[16] M. Burzynski, W. Cudny, and W. Kosinski, "Traffic flow simulation cellular automata with fuzzy rules approach," in $C h$. Advances in Soft Computing, Proc. of the Sixth Int. Conference on Neural Network and Soft Computing, pp. 808-813, Zakopane, Poland, 2003.

[17] S. Maerivoet and B. De Moor, "Cellular automata models of road traffic," Physics Reports, vol. 419, no. 1, pp. 1-64, 2005.

[18] P. Prokopowicz, "Flexible and simple methods of calculations on fuzzy numbers with the ordered fuzzy numbers model," in Artificial Intelligence and Soft Computing, vol. 7894 of Lecture Notes in Computer Science, pp. 365-375, Springer, Berlin, Heidelberg, 2013.

[19] R. Kozik, M. Choraś, A. Flizikowski, M. Theocharidou, V. Rosato, and E. Rome, "Advanced services for critical infrastructures protection," Journal of Ambient Intelligence and Humanized Computing, vol. 6, no. 6, pp. 783-795, 2015.

[20] E. Velizarova, E. Sotirova, K. Atanassov, P. Vassilev, and S. Fidanova, "On the game method for the forest fire spread modelling with considering the wind effect," in Proceedings of the 2012 6th IEEE International Conference Intelligent Systems, IS, pp. 216-220, Bulgaria, 2012.

[21] S. Darlington, M. Brocchetto, and D. Ford, Fire rips through crowded brazil nightclub, killing 233, https://edition.cnn.com/ 2013/01/27/world/americas/brazil-nightclub-fire/index.html.

[22] S. Darlington and C. J. Carter, Brazil nightclub fire: 'like a war zone' with bodies piled, http://edition.cnn.com/2013/01/ 28/world/americas/brazil-nightclub-fire/index.html.

[23] T. Vince, J. Molnar, and R. Bucko, "A survey of urban vehicular sensing platforms," Transactions of KMOSU, vol. 4, no. 1, pp. $150-153,2010$. 
[24] A. Stachowiak, K. Dyczkowski, A. Wójtowicz, P. Żywica, and M. Wygralak, "A bipolar view on medical diagnosis in OvaExpert system," Advances in Intelligent Systems and Computing, vol. 400, pp. 483-492, 2016.

[25] K. Dyczkowski, "A less cumulative algorithm of mining linguistic browsing patterns in the world wide web," in Proceedings of the 5th EUSFLAT Conference, Ostrava, Czech Republic, 2007.

[26] J. Czerniak, H. Zarzycki, and D. Ewald, AAO as a new strategy in modeling and simulation of constructional problems optimization, Simulation Modelling Practice and Theory, 2017.

[27] J. Czerniak, G. Smigielski, D. Ewald, and M. Paprzycki, "New proposed implementation of ABC method to optimization of water capsule flight," in Federated Conference on Computer Science and Information Systems, IEEE Digital Library, ACSIS 5, pp. 489-493.

[28] [link]. URL http://en.wikipedia.org/wiki/Kiss_nightclub_fire \#mediaviewer/Kissnightclub.svg.

[29] [link]. URL http://en.wikipedia.org/wiki/Cocoanut_Grove_fire \#The_club.

[30] I. Zolotová and R. Hošák, "Objects for visualization of process data in supervisory control," in Aspects of Computational Intelligence: Theory and Applications, vol. 2 of Topics in Intelligent Engineering and Informatics, pp. 51-61, Springer, Berlin, Germay, 2013.

[31] E. Mikołajewska and D. Mikołajewski, "Non-invasive EEGbased brain-computer interfaces in patients with disorders of consciousness," Military Medical Research, vol. 1, no. 1, p. 14, 2014.

[32] C. Burstedde, K. Klauck, A. Schadschneider, and J. Zittartz, "Simulation of pedestrian dynamics using a two-dimensional cellular automaton," Physica A: Statistical Mechanics and its Applications, vol. 295, no. 3-4, pp. 507-525, 2001.

[33] A. Kirchner and A. Schadschneider, "Simulation of evacuation processes using a bionics-inspired cellular automaton model for pedestrian dynamics," Physica A: Statistical Mechanics and its Applications, vol. 312, no. 1-2, pp. 260-276, 2002.

[34] A. Schadschneider, W. Klingsch, H. Klüpfel, T. Kretz, C. Rogsch, and A. Seyfried, "Evacuation dynamics: empirical results, modeling and applications," in Encyclopedia of complexity and systems science, pp. 3142-3176, Springer, 2009.

[35] Y. Suma, D. Yanagisawa, and K. Nishinari, "Anticipation effect in pedestrian dynamics: modeling and experiments," Physica A: Statistical Mechanics and its Applications, vol. 391, no. 1-2, pp. 248-263, 2012.

[36] [link]. URL http://edition.cnn.com/2013/01/28/world/americas/brazil-nightclub-fire/.

[37] [link]. URL http://www.bostonfirehistory.org/firestoryl1281942 .html.

[38] G. Śmigielski, R. Dygdała, H. Zarzycki, and D. Lewandowski, "Real-time system of delivering water-capsule for firefighting," Advances in Intelligent Systems and Computing, vol. 534, pp. 102111, 2017.

[39] F. E. Petry, M. A. Cobb, D. Ali et al., "Fuzzy Spatial Relationships and Mobile Agent Technology in Geospatial Information Systems," in Applying Soft Computing in Defining Spatial Relations, vol. 106 of Studies in Fuzziness and Soft Computing, pp. 123-155, Physica-Verlag HD, Heidelberg, 2002.

[40] R. A. Angryk and F. E. Petry, "Mining multi-level associations with fuzzy hierarchies," in Conference: Fuzzy Systems, FUZZ '05. The 14th IEEE International, pp. 785-790, 2005.
[41] A. Marszal ek and T. Burczynski, "Modeling and forecasting financial time series with ordered fuzzy candlesticks," Information Sciences, vol. 273, pp. 144-155, 2014.

[42] A. Marszałek and T. Burczyński, "Modelling financial high frequency data using ordered fuzzy numbers," in Artificial Intelligence and Soft Computing, vol. 7894 of Lecture Notes in Computer Science, pp. 345-352, Springer, Berlin, Heidelberg, 2013.

[43] L. A. Zadeh, "Fuzzy sets," Information and Control, vol. 8, no. 3, pp. 338-353, 1965.

[44] G. J. Klir, "Chapter 2 Fuzzy logic," in Soft Computing and Intelligent Data Analysis in Oil Exploration, F. A. M. Nikravesh and L. Zadeh, Eds., vol. 51 of Developments in Petroleum Science, pp. 33-49, Elsevier, 2003.

[45] D. Dubois, H. Prade, and G. Richard, "Multiple-valued extensions of analogical proportions," Fuzzy Sets and Systems, vol. 292, pp. 193-202, 2016.

[46] M. A. Kłopotek, S. T. Wierzchoń, and M. Michalewicz, in Fuzzy reals with algebraic operations: algorithmic approach, pp. 311-320, the IIS'2002 Symposium on Intelligent Information Systems, 2002.

[47] W. Kosiński, "Evolutionary algorithm determining defuzzyfication operators," Engineering Applications of Artificial Intelligence, vol. 20, no. 5, pp. 619-627, 2007.

[48] W. T. Dobrosielski, J. M. Czerniak, J. Szczepański, and H. Zarzycki, "Triangular expanding, a new defuzzification method on ordered fuzzy numbers," Advances in Intelligent Systems and Computing, vol. 642, pp. 605-619, 2017.

[49] Y. Zheng, B. Jia, X. G. Li, and N. Zhu, "Evacuation dynamics with fire spreading based on cellular automaton," Physica A: Statistical Mechanics and its Applications, vol. 390, no. 18-19, pp. 3147-3156, 2011.

[50] J. Hu, H. Sun, G. Gao, J. Wei, and L. You, "The group evacuation behavior based on fire effect in the complicated threedimensional space," Mathematical Problems in Engineering, vol. 2014, Article ID 949280, 7 pages, 2014.

[51] J. Czerniak, W. Dobrosielski, and I. Filipowicz, "Some cases of comparing fuzzy numbers using defuzzificators on the catalog of ofn shapes," in Theory and Applications of Ordered Fuzzy Numbers: A Tribute to Professor Witold Kosinski, P. Prokopowicz, J. Czerniak, D. Mikolajewski, L. Apiecionek, and D. Slezak, Eds., vol. 356 of Studies in Fuzziness and Soft Computin, pp. 99134, Springer, 2017.

[52] J. Czerniak, "The OFNAnt method based on ant colony optimization used to solve the tsp," in Theory and Applications of Ordered Fuzzy Numbers: A Tribute to Professor Witold Kosinski, P. Prokopowicz, J. Czerniak, D. Mikolajewski, L. Apiecionek, and D. Slezak, Eds., vol. 356 of Studies in Fuzziness and Soft Computing, pp. 209-224, Springer, 2017.

[53] T. Saelao and S. Patvichaichod, "The computational fluid dynamic simulation of fire evacuation from the student dormitory," American Journal of Applied Sciences, vol. 9, no. 3, pp. 429435, 2012.

[54] H. Zarzycki, J. Czerniak, and W. Dobrosielski, "Aplication of ordered fuzzy numbers to detect trends in the nasdaq composite index," in Theory and Applications of Ordered Fuzzy Numbers: A Tribute to Professor Witold Kosinski, P. Prokopowicz, J. Czerniak, D. Mikolajewski, L. Apiecionek, D. Slezak, and P. the nasdaq composite index, Eds., vol. 356 of Studies in Fuzziness and Soft Computing, pp. 197-208, Springer, 2017. 
[55] W. Dobrosielski, J. Czerniak, H. Zarzycki, and J. Szczepanski, "Fuzzy numbers applied to a heat furnace control," in Theory and Applications of Ordered Fuzzy Numbers: A Tribute to Professor Witold Kosinski, P. Prokopowicz, J. Czerniak, D. Mikolajewski, L. Apiecionek, and D. Slezak, Eds., vol. 356 of Studies in Fuzziness and Soft Computing, pp. 271-290, Springer, 2017. 


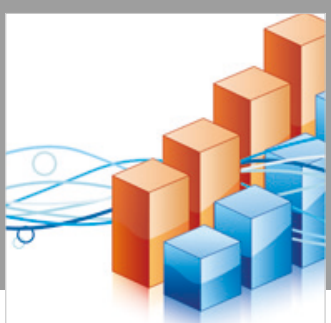

Advances in

Operations Research

\section{-n-m}
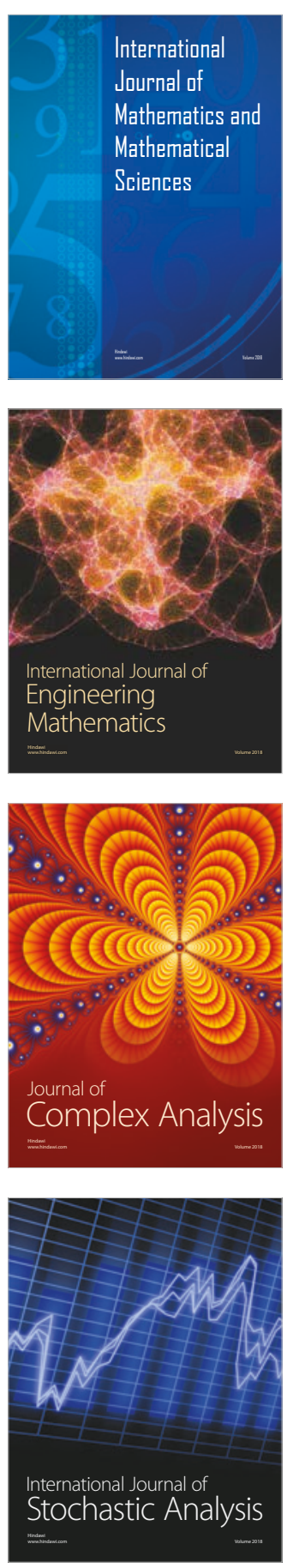
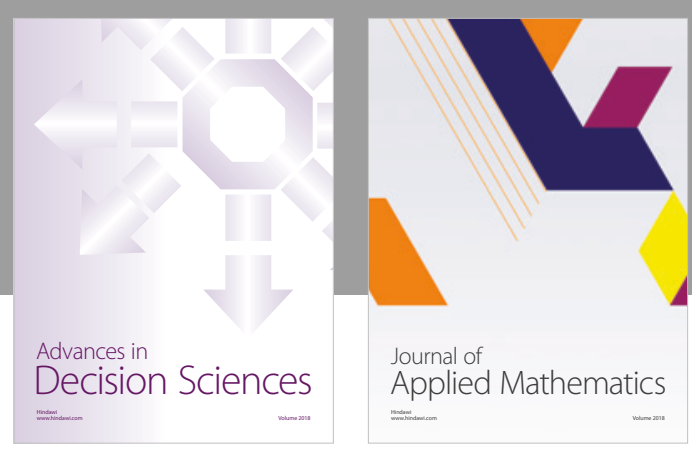

Journal of

Applied Mathematics
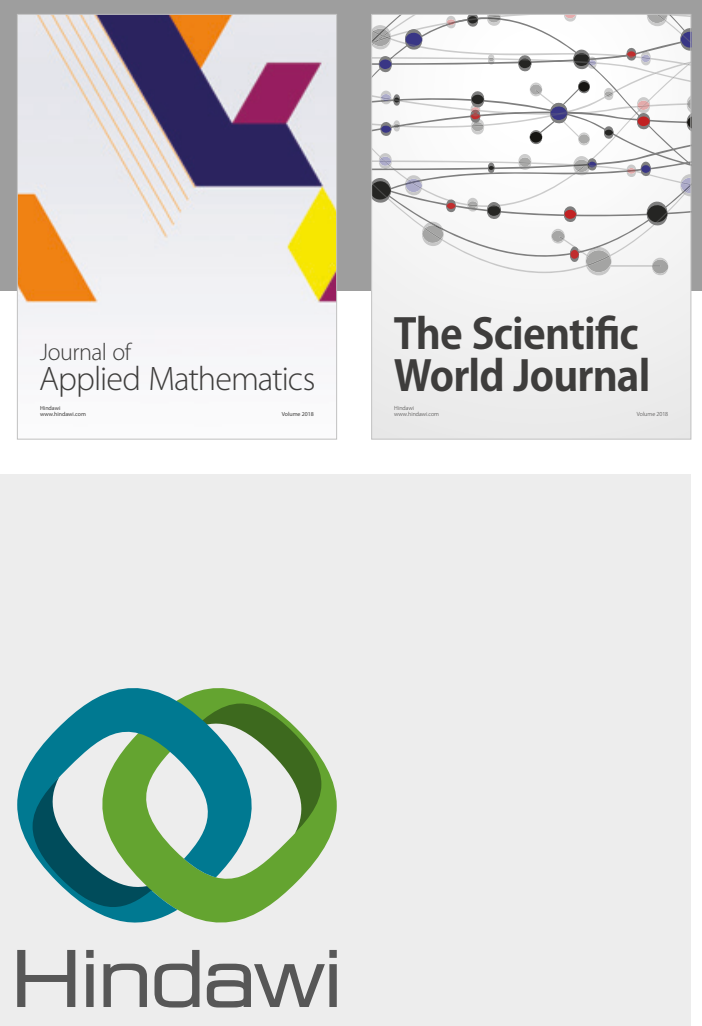

Submit your manuscripts at

www.hindawi.com

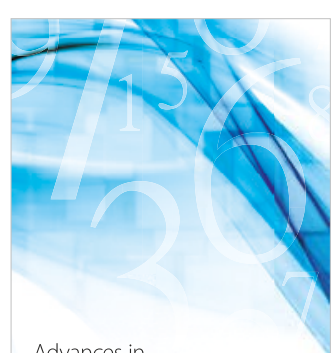

Advances in
Numerical Analysis
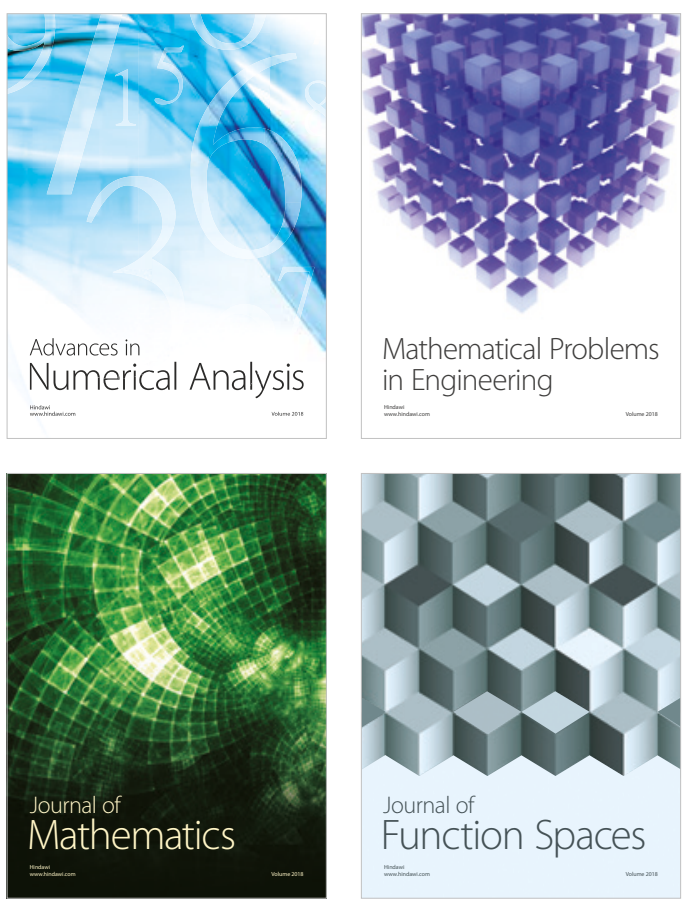

Mathematical Problems in Engineering

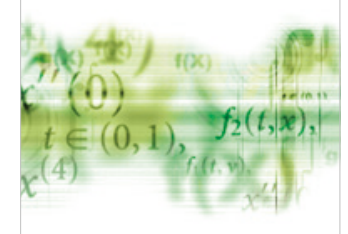

International Journal of

Differential Equations

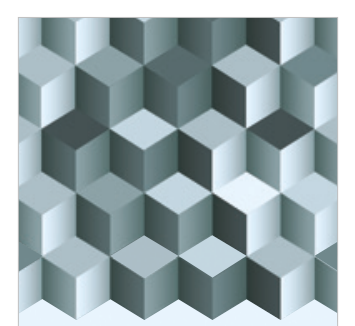

Journal of

Function Spaces
The Scientific

World Journal

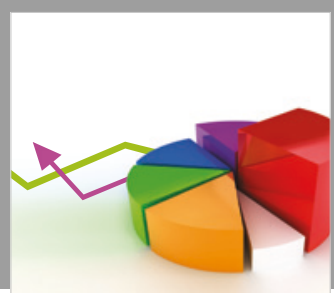

Journal of

Probability and Statistics
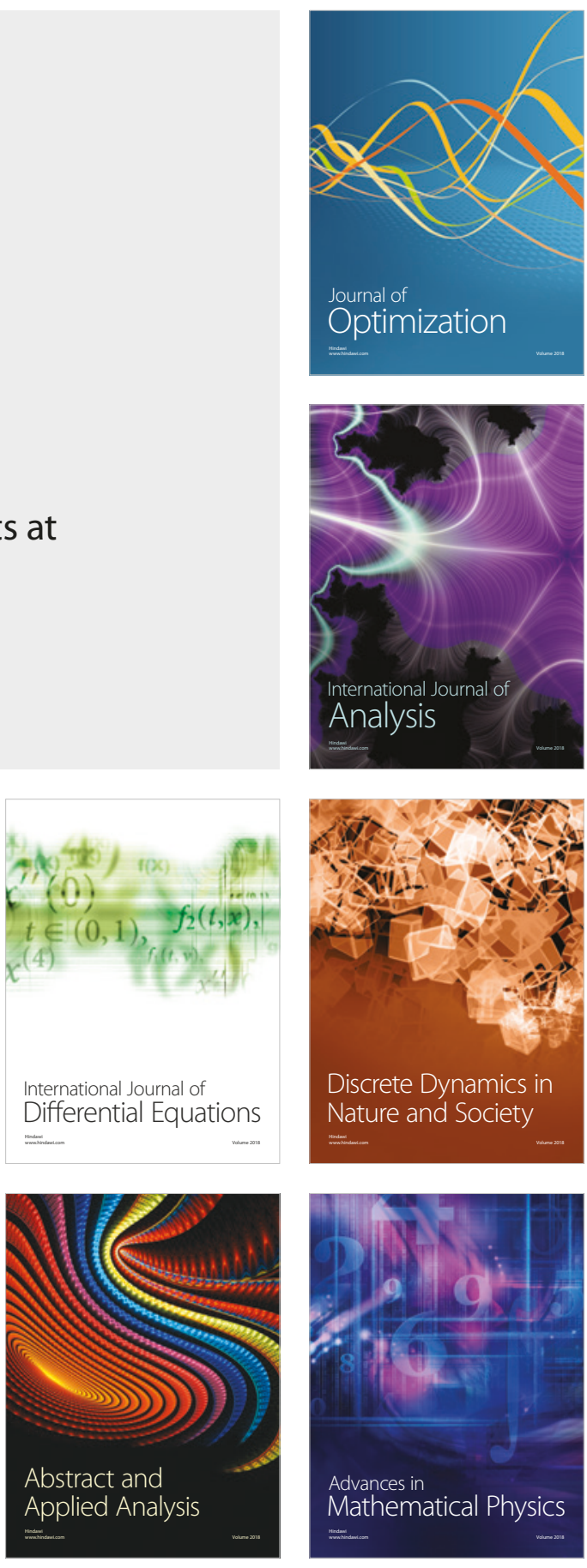